\title{
AKTIVITAS FILTRAT CENDAWAN Lasiodiploida theobromae SEBAGAI INHIBITOR PERTUMBUHAN TANAMAN BAYAM (Amaranthus spp. L.)
}

\author{
FILTRATE ACTIVITIES OF FUNGI Lasiodiploida theobromae \\ AS GROWTH INHIBITOR IN SPINACH (Amaranthus spp. L.)
}

\author{
Syahbudin Hasibuan, Ahmad Rafiqi Tantawi, Gusmeizal \\ Program Studi Agroteknologi Fakultas Pertanian Universitas Medan Area \\ Jl. Kolam No. 1 Medan Estate Medan \\ Korespondensi : syahbudinhasibuan@yahoo.co.id
}

Diterima 10 Agustus 2015 /Disetujui 15 Desember 2015

\begin{abstract}
ABSTRAK
Lasiodiploidia theobromae merupakan cendawan patogen yang umum ditemukan pada berbagai inang. Cendawan ini diketahui menghasilkan senyawa metabolik berupa theobroksida yang merupakan senyawa bahan alami epoxy cyclohexene. Theobroksida mampu menginduksi pembungaan, menginduksi tuberisasi tanaman kentang pada lingkungan non-inducing dan berkaitan dengan inhibisi perpanjangan batang tanaman. Sebagai inhibitor alami yang diisolasi dari kultur filtrat cendawan Lasiodiploidia theobromae, aktivitas senyawa theobroksida telah diuji di lahan percobaan Fakultas Pertanian Universitas Medan Area sejak bulan Mei sampai bulan Juli 2015. Ekstrak diuji pada tanaman bayam (Amaranthus spp L.) yang percobaannya disusun dalam rancangan acak kelompok sederhana dengan faktor perlakuan yaitu konsentrasi Filtrat Lasiodiploidia theobromae yang terdiri atas tiga taraf yaitu 0, 100, 200 dan 300 ppm. Hasil uji aktivitas menunjukkan bahwa aplikasi theobrokside menghambat pertumbuhan pada peubah tinggi tanaman,luas daun dan jumlah daun tanaman bayam.
\end{abstract}

Kata kunci: Cendawan, Filtrat, Lasiodiploidia theobromae, Theobroksida

\begin{abstract}
Lasiodiploidia theobromae is a fungal pathogen which is usually found in various host plants. This fungi is recognized to produce metabolic compounds namely theobroxide, a natural compound of epoxy cyclohexene. Theobroxide has ability to induce flowering initiation, induce tuberisation in potato plants in non-inducing environment also related to inhibition of plant stem elongation. As natural inhibitors isolated from filtrate culture of Lasiodiploidia theobromae, a research to evaluate activities of theobroxide was conducted in experimental station belonged to Faculty of Agriculture, University of Medan Area, started from Mei until July 2015. This Experiment was arranged in simple randomized block design (RBD) with filtrate Lasiodiploidia theobromae concentration as treatment factor. The treatment comprised four levels i.e. 0,100,200, and $300 \mathrm{ppm}$. Results showed that application of theobroxide could significantly inhibit plant height, leave number and leaf area of spinach.
\end{abstract}

Keywords :Filtrate, Fungus, Lasiodiploida theobromae, Theobroxide 


\section{PENDAHULUAN}

Lasiodiploida theobromae merupakan cendawan patogenik yang selama ini dikenal dapat menyebabkan penyakit pada berbagai tanaman buah-buahan dan umbiumbiaan. Cendawan tersebut dijumpai pada buah dan umbi terutama sekali pada masa penyimpanan. Pada sisi lain, meskipun dikenal sebagai patogen, cendawan Lasiodiploida theobromae belakangan diketahui terbukti efektif dalam menginduksi umbi mikro tanaman kentang. Peng Li et al. (2005) dalam Larekeng (2008) menjelaskan bahwa dari hasil isolasi kultur filtrat cendawan dapat diperoleh senyawa (3R, 6S)-6-Hydroxylasiodiplodin yang mampu mempercepat pertumbuhan umbi mikro kentang. Sejalan dengan itu, Yang et al. (2004) melaporkan bahwa kultur filtrat cendawan Lasiodiploida theobromae menghasilkan senyawa yang memiliki aktivitas biologis menarik yang disebut dengan senyawa theobroksida. Theobroksida merupakan senyawa berbahan alami epoxy cyclohexene yang dilaporkan mampu menginduksi pembungaan tanaman morning glory (Pharbitis nil) (Gao et al., 2005), menginduksi tuberisasi tanaman kentang pada lingkungan non induktif (Yoshihara et al., 2010), dan berkaitan dengan penghambatan perpanjangan batang tanaman bayam (Spinacia oleraceae L.) (Kong et al., 2005)

Aktivitas metabolik senyawa theobroksida diduga berhubungan dengan sintesis asam jasmonat (jasmonic acid) dan metil ester (metil jasmonat) (Chen et al., 2010). Mekanisme hipotetikal kerja theobroksida dalam menghambat pertumbuhan sepertinya adalah dengan cara meningkatkan laju biosintesis asam jasmonat. Asam Jasmonat (Gambar 1) adalah senyawa bersifat volatil (mudah menguap) yang terbentuk melalui biosintesis dari asam linoleat-bebas oleh enzim lipoksigenase dan berfungsi menghambat pertumbuhan beberapa bagian tumbuhan tertentu dan sangat kuat mendorong terjadinya penuaan daun (Salisbury dan Roos, 1995).

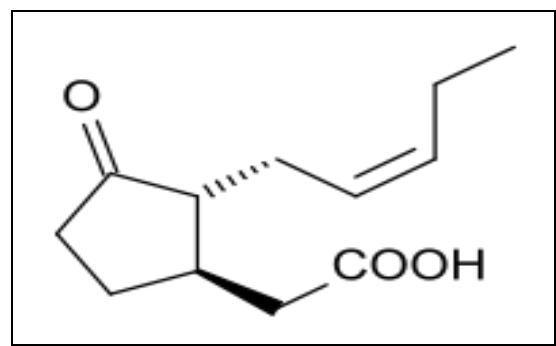

Gambar 1a. Struktur struktur asam jasmonat

(Sumber: Yang et al., 2004)

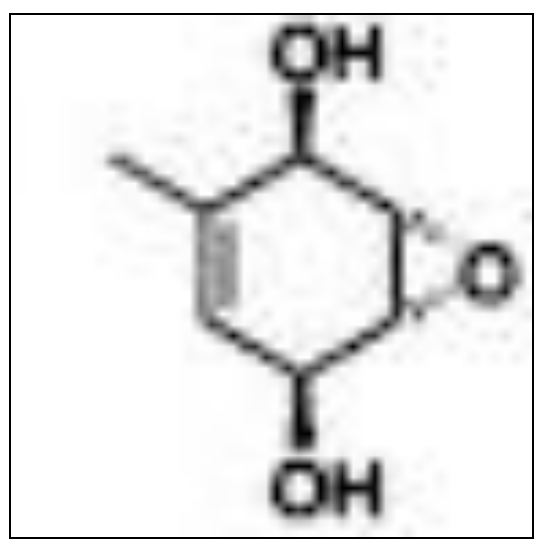

(b)

Gambar 1b. Gambar struktur theobroksida (Sumber: Yang et al., 2004)

Hasil-hasil penelitian menunjukkan bahwa terhambatnya pertumbuhan oleh aktivitas metabolik asam jasmonat ternyata berhubungan dengan terganggunya biosintesis dan bioaktivitas hormon giberelin dalam proses pertumbuhan tanaman. Kong et al., (2005) melaporkan bahwa aplikasi theobroksida dapat menekan biosintesis giberelin (GA1) pada tanaman kentang. Selain itu, aplikasi theobroksida juga mampu meningkatkan produksi ubi pada 
beberapa tanaman penghasil ubi termasuk kentang.

Berdasarkan uraian tersebut, untuk mempelajari serta memverifikasi efektivitas theobroksida dalam menghambat pertumbuhan tanaman, hasil isolasi kultur filtrat dari cendawan Lasiodiploida theobromae diuji aktivitas inhibitor pada tanaman bayam (Amaranthus spp. L).

\section{BAHAN DAN METODE}

Penelitian dilakukan di laboratorium Agroteknologi Fakultas Pertanian Universitas Medan Area. Percobaan dilakukan mulai bulan Mei sampai Juli 2015. Sumber inokulum cendawan Lasiodiplodia theobromae diperoleh dari buah dan batang tanaman kakao di kebun masyarakat Desa Sibiru-biru, Deli Tua dan Namorambe Kabupaten Deliserdang. Cendawan Lansiodiplodia theobromae diisolasi dari tanaman yang memperlihatkan gejala penyakit blendok dan busuk buah. Organ tanaman yang teridentifikasi blendok dipotong- potong sepanjang $\pm 1-2 \mathrm{~cm}$. Potongan tersebut disterilisasi dengan menggunakan alkohol $70 \%$ dan kemudian dibilas dengan aquades steril sebanyak tiga kali. Inokulum selanjutnya diinkubasi pada cawan petri yang telah berisi media PDA selama 4-6 hari. Setelah diperoleh biakan murni, kemudian diperbanyak dengan cara memindahkan cendawan dengan menggunakan cork borer ke media PDA yang baru.

Biakan Cendawan Lansiodiplodia theobromae di media PDA (Gambar 2), selanjutnya dipindahkan ke dalam botol berisi media Czapek Dox cair menggunakan cork borer, dikocok dengan shaker selama 6 hari pada kecepatan $75-80$ rpm dengan suhu ruangan kultur $20^{\circ} \mathrm{C}$. Filtrat biakan cendawan pada media Czapek Dox cair disaring menggunakan kertas saring. Filtrat kemudian disentrifugasi dengan kecepatan 10.000 rpm, selama 15 menit, kemudian disaring kembali dengan membran mikrofilter dengan ukuran pori $0.2 \mu \mathrm{m}$. Filtrat yang diperoleh diencerkan sesuai konsentrasi dari masing-masing perlakuan.
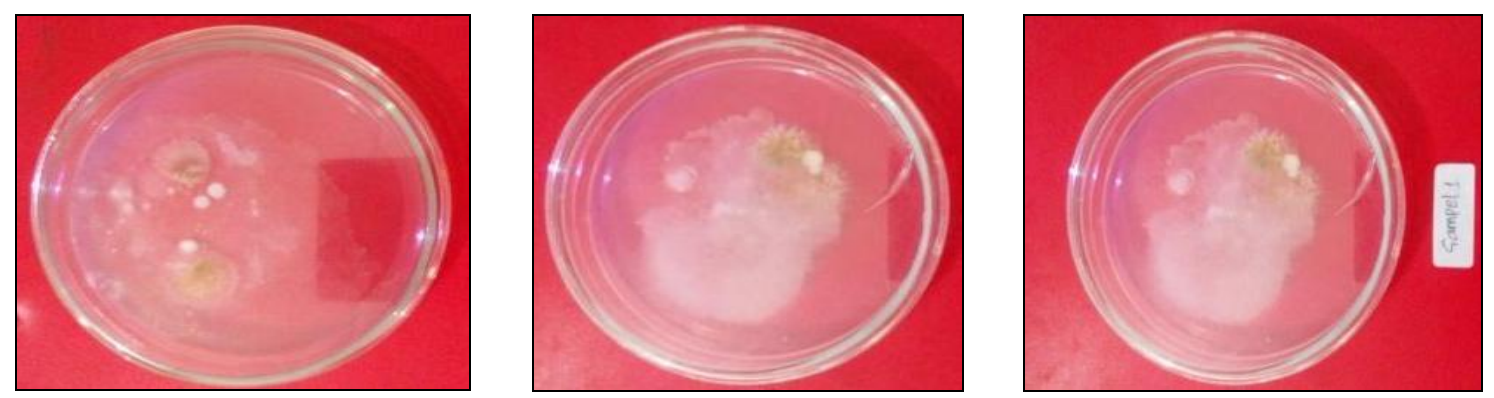

Gambar 2. Perkembangan cendawan Lansoplodia theobromae pada media PDA

Uji lapangan terhadap aktivitas filtrat cendawan Lasiodiploida theobromae dilakukan di kebun masyarakat Desa Bantan Kecamatan Medan Tembung Kota Medan dengan ketinggian tempat $\pm 20 \mathrm{~m} \mathrm{dpl}$, jenis tanah alluvial. Percobaan lapang disusun dalam rancangan acak kelompok sederhana dengan faktor perlakuan yaitu konsentrasi filtrat cendawan Lasiodiploida theobromae $(0,100,200$ dan 300 ppm) dan diulang 3 kali. Bioindikator yang digunakan adalah tanaman bayam cabut/bayam putuh (Amaranthus tricolor. L). Filtrat cendawan Lasiodiploida theobromae diaplikasikan 
pada umur 10 Hari Setelah Tanam (HST) dengan cara disemprotkan ke semua bagian tanaman. Interval pemberian setiap 7 hari sekali.

Sebelum dilakukan penanaman, tanah terlebih dahulu diolah, kemudian di buat bedengan berukuran $100 \times 100 \mathrm{~cm}$ dengan ketinggian $25 \mathrm{~cm}$. Jarak antar bedengan 40 $\mathrm{cm}$. Setelah bedengan selesai, permukaan tanah diberi pupuk kandang kotoran sapi yang dicampur dengan kompos dengan perbandingan $1: 1$ dengan dosis $1 \mathrm{~kg} / \mathrm{plot}$, kemudian plot dibiarkan selama 4 hari. Penanaman dilakukan dengan cara menyebar benih ke setiap plot percobaan sebanyak $0.5 \mathrm{~g} /$ plot dan terlebih dahulu benih dicampur dengan pasir agar benih merata pada setiap plot. Penyiraman dilakukan pada pagi dan sore hari. Pengendalian hama dan penyakit dilakukan dengan penyemprotan pestisida yang mengandung margosin dan glikosida flafonoid seperti matador dengan konsentrasi 3-5 cc/liter air. Pengamatan dilakukan pada peubah pertumbuhan yaitu : tinggi tanaman, jumlah daun dan luas daun.

Untuk mengetahui apakah terdapat pengaruh perlakuan, data dianalisis dengan menggunakan analisis varians (statistik uji F). Apabila perlakuan berpengaruh nyata, maka dilanjutkan dengan jarak berganda Duncan pada taraf nyata 5\%.

\section{HASIL DAN PEMBAHASAN}

\section{Tinggi tanaman}

Hasil analisis terhadap peubah tinggi tanaman menunjukkan bahwa peningkatan konsentrasi fitrat Lasiodiploida theobromae memberikan efek penghambatan pertumbuhan semakin kuat pada peubah tinggi tanaman pada semua waktu pengamatan (Tabel 1 ).

Tabel 1. Pengaruh konsentrasi filtrat cendawan Lasiodiploida theobromae terhadap tinggi tanaman

\begin{tabular}{cccccc}
\hline \multirow{2}{*}{ Perlakuan $(\mathrm{ppm})$} & \multicolumn{5}{c}{ Rataan Tinggi Tanaman $(\mathrm{cm})$} \\
\cline { 2 - 6 } & $7 \mathrm{HSA}$ & $12 \mathrm{HSA}$ & $17 \mathrm{HSA}$ & $22 \mathrm{HSA}$ & $27 \mathrm{HSA}$ \\
\hline 0 & $13,9 \mathrm{a}$ & $17,2 \mathrm{a}$ & $22,5 \mathrm{a}$ & $26,6 \mathrm{a}$ & $32,4 \mathrm{a}$ \\
100 & $12,8 \mathrm{ab}$ & $16,9 \mathrm{a}$ & $19,9 \mathrm{~b}$ & $23,1 \mathrm{~b}$ & $26,2 \mathrm{~b}$ \\
200 & $12,4 \mathrm{~b}$ & $14,8 \mathrm{~b}$ & $17,1 \mathrm{c}$ & $20,0 \mathrm{c}$ & $23,3 \mathrm{c}$ \\
300 & $11,7 \mathrm{c}$ & $13,4 \mathrm{c}$ & $16,3 \mathrm{c}$ & $17,9 \mathrm{~d}$ & $21,1 \mathrm{~d}$ \\
\hline
\end{tabular}

Keterangan : Nilai rata-rata yang ditandai huruf yang sama tidak berbeda nyata menurut uji jarak berganda Duncan pada taraf $5 \%$

Konsentrasi theobroksida $300 \mathrm{ppm}$ memberikan efek penghambatan tertinggi yang tergambar pada rata-rata tinggi tanaman $21,1 \mathrm{~cm}$ pada pengamatan 37 hari setelah tanam atau 27 hari setelah aplikasi (HSA) dan efek penghambatan menurun seiring dengan menurunnya konsentrasi filtrat yaitu $23,3 \mathrm{~cm}$ dengan perlakuan 200 ppm, 26,2 cm dengan perlakuan 100 ppm dan $32,4 \mathrm{~cm}$ tanpa pemberian filtrat. Pola pengaruh penghambatan pertumbuhan dari fitrat Lasiodiploida theobromae pada setiap waktu pengamatan ditunjukkan pada Gambar 3. Kong et al. (2006) melaporkan bahwa penyemprotan filtrat senyawa theobroksida hasil isolasi dari cendawan Lasiodiploida theobromae ke daun tanaman bayam (spinacia oleracea L) mampu menghambat perpanjangan batang. Selain menekan pertumbuhan, Geo et al, (2005) melaporkan juga bahwa aplikasi theobroksida dapat merangsang (stimulus) 
pembungaan tanaman morning glory (pharbitis nil) dan mampu meningkatkan produksi umbi kentang (Yoshihara et al., 2000). Sepertinya efek fisiologis senyawa theobroksida dalam menghambat partumbuhan memiliki kemiripan dengan senyawa heterocycle yang mengandung nitrogen seperti Paklobutrazol. Chaney, (2004) menjelaskan bahwa paklobutrazol dapat menghambat biosintesis giberelin pada sub- apikal dengan cara memblokir konversi entkaurin menjadi ent-kaurenat yang merupakan prekursor pembentukan senyawa giberelin. Nampaknya teobroksida mampu mensupresi biosintesis giberelin yang berdampak pada menurunnya laju pembelahan sel dan pada akhirnya akan berdampak pula pada pertumbuhan tanaman.

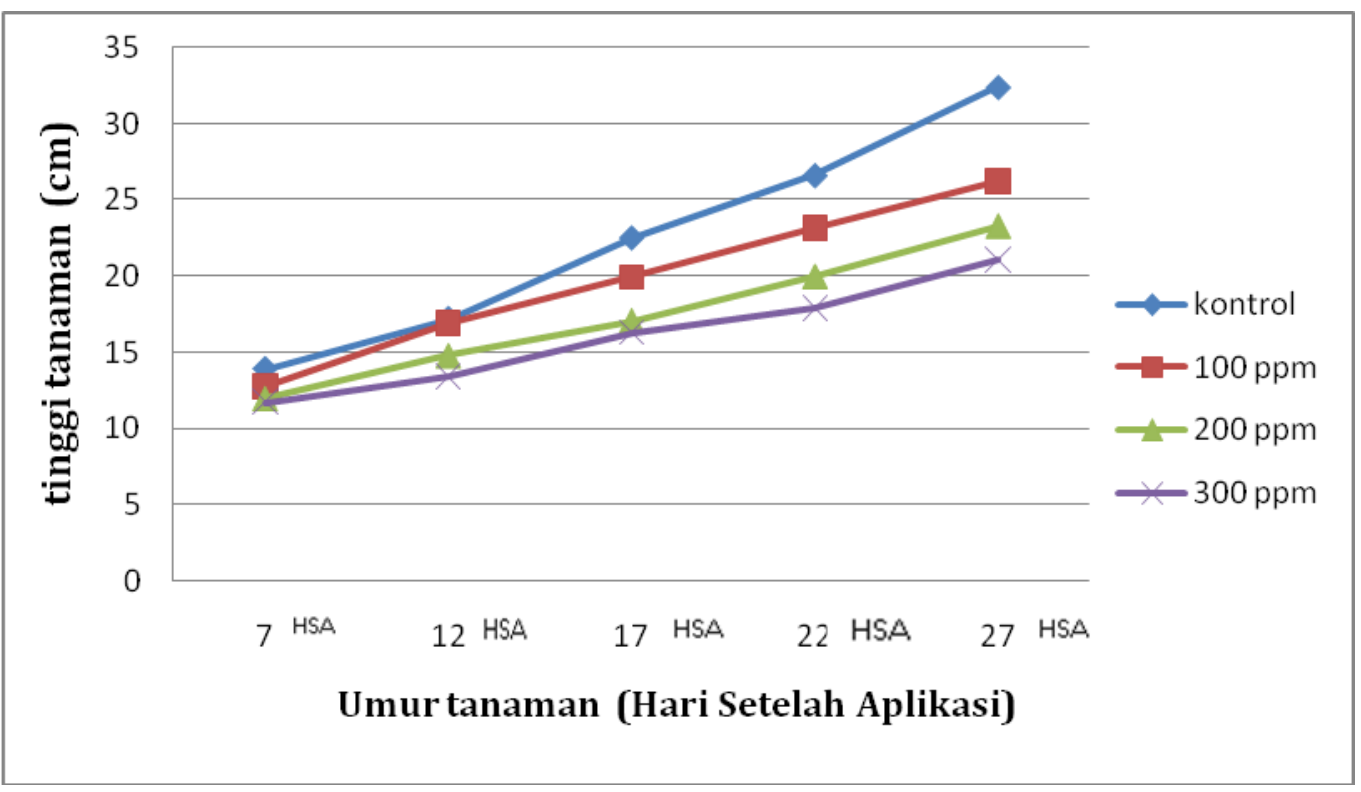

Gambar 3. Pola pertambahan tinggi tanaman bayam yang diberi filtrat cendawan Lasiodiploida theobromae

\section{Luas Daun}

Hasil analisis terhadap peubah luas daun pada tiap-tiap pengamatan dapat dilihat pada Tabel 2. Peningkatan konsentrasi filtrat cendawan, bukan saja meningkatkan hambatan terhadap perpanjangan batang, namun mampu menekan pertambahan luas daun pada semua waktu pengamatan. Efek inhibitor tertinggi terlihat dari perlakuan dengan konsentrasi filtrat 300 ppm pada waktu pengamatan 27 hari setelah aplikasi (HSA) yang tergambar pada luas daun yang hanya sebesar $48,6 \mathrm{~cm}^{2}$ per tanaman. Luas daun meningkat seiring dengan penurunan konsentrasi filtrat Lasiodiploida theorbomae.

Berbeda halnya dengan senyawa anti giberelin, aplikasi filtrat juga berpotensi menghambat pertumbuhan tanaman dengan cara meningkatkan laju biosintesis asam jasmonat. Akumulasi asam jasmonat akan menekan laju pertumbuhan organ tanaman. Salisbury dan Ross (1995) menjelaskan bahwa asam jasmonat tergolong senyawa bersifat inhibitor yang telah diketahui menghambat pertumbuhan beberapa bagian tanaman dan sangat kuat mendorong terjadinya penuaan daun. 
Selain itu, Kong et al., (2005b) melaporkan bahwa aplikasi theobroksida pada tanaman kentang dapat menekan biosintesis Giberelin. Kelihatannya, aplikasi theobroksida bukan saja berhubungan dengan peningkatan sintesis asam jasmonat akan tetapi juga menghambat sintesis giberelin. Peningkatan asam jasmonat disatu sisi dan penurunan kadar giberelin disisi yang lain menyebabkan terhambatnya pertumbuhan daun tanaman.

Tabel 2. Pengaruh konsentrasi filtrat cendawan Lasiodiploida theobromae terhadap luas daun per tanaman

\begin{tabular}{cccccc}
\hline Perlakuan $(\mathrm{ppm})$ & \multicolumn{5}{c}{ Rataan Luas Daun $\left(\mathrm{cm}^{2}\right)$} \\
\cline { 2 - 6 } & $7 \mathrm{HSA}$ & $12 \mathrm{HSA}$ & $17 \mathrm{HSA}$ & $22 \mathrm{HSA}$ & $27 \mathrm{HAS}$ \\
\hline 0 & $21,7 \mathrm{a}$ & $27,4 \mathrm{a}$ & $38,9 \mathrm{a}$ & $54,6 \mathrm{a}$ & $66,9 \mathrm{a}$ \\
100 & $21,3 \mathrm{ab}$ & $26,8 \mathrm{ab}$ & $36,5 \mathrm{ab}$ & $46,5 \mathrm{~b}$ & $57,5 \mathrm{~b}$ \\
200 & $18,6 \mathrm{c}$ & $26,4 \mathrm{bc}$ & $33,9 \mathrm{c}$ & $41,1 \mathrm{c}$ & $52,7 \mathrm{c}$ \\
300 & $18,6 \mathrm{c}$ & $25,4 \mathrm{c}$ & $32,2 \mathrm{c}$ & $38,9 \mathrm{c}$ & $48,6 \mathrm{~d}$ \\
\hline
\end{tabular}

Keterangan : Nilai rata-rata yang ditandai huruf yang sama tidak berbeda nyata menurut uji jarak berganda Duncan pada taraf $5 \%$

\section{Jumlah Daun}

Hasil analisis terhadap peubah jumlah daun per tanaman pada tiap-tiap pengamatan dapat dilihat pada Tabel 3 .
Aplikasi filtrat cendawan Lasiodiploida theobromae, ternyata juga menurunkan jumlah daun pada tanaman bayam pada semua waktu pengamatan.

Tabel 3. Pengaruh konsentrasi filtrat cendawan Lasiodiploida theobromae terhadap Jumlah Daun per tanaman

\begin{tabular}{cccccc}
\hline \multirow{2}{*}{$\begin{array}{c}\text { Perlakuan } \\
(\mathrm{ppm})\end{array}$} & $7 \mathrm{HSA}$ & $12 \mathrm{HSA}$ & $17 \mathrm{HSA}$ & $22 \mathrm{HSA}$ & $27 \mathrm{HSA}$ \\
\cline { 2 - 6 } & $3,9 \mathrm{a}$ & $5,4 \mathrm{a}$ & $8,2 \mathrm{a}$ & $10,3 \mathrm{a}$ & $12,9 \mathrm{a}$ \\
100 & $3,7 \mathrm{a}$ & $5,1 \mathrm{a}$ & $7,5 \mathrm{~b}$ & $9,0 \mathrm{~b}$ & $11,0 \mathrm{~b}$ \\
200 & $3,5 \mathrm{a}$ & $4,7 \mathrm{bc}$ & $6,4 \mathrm{c}$ & $8,7 \mathrm{c}$ & $9,8 \mathrm{c}$ \\
300 & $3,0 \mathrm{~b}$ & $4,5 \mathrm{c}$ & $6,2 \mathrm{c}$ & $8,2 \mathrm{c}$ & $9,6 \mathrm{c}$ \\
\hline
\end{tabular}

Keterangan : Nilai rata-rata yang ditandai huruf yang sama tidak berbeda nyata menurut uji jarak berganda Duncan pada taraf $5 \%$

Aplikasi theobroksida menurunkan kadar giberelin pada tanaman melalui penghambatan sintesis giberelin. Terhambatnya produksi giberelin menyebabkan penurunan laju pembelahan sel dan diferensiasi sel sehingga pertumbuhan vegetatif menjadi menurun (Weaver, 1972).

Sebagaimana telah disinggung, theobroksida juga mampu meningkatkan laju biosintesis asam jasmonat, senyawa tergolong inhibitor yang telah diketahui menghambat pertumbuhan beberapa bagian tanaman. Kehadiran asam jasmonat dan menurunnya kandungan giberelin bisa jadi faktor penyebab dormansi kuncup aksilar, sehingga tunas daun terhambat tumbuh. Namun perlu penelitian lebih lanjut tentang kemampuan theobroksida dalam dormansi kuncup aksilar.

Merujuk pada mekanisme penghambatan theobroksida terhadap pertumbuhan tanaman, senyawa ini memiliki prospek dalam upaya rekayasa budidaya tanaman khususnya tanaman-tanaman yang potensi 
ekonominya terkondisikan oleh besarnya konsentrasi hormon giberelin, tanaman kentang misalnya. Diferensiasi stolon menjadi umbi pada tanaman kentang diketahui sangat dipengaruhi oleh kehadiran giberelin di akar. Eksistensi giberelin di akar menyebabkan terjadinya pemanjangan stolon. Oleh karena itu, senyawa-senyawa yang memperlihatkan aktivitas anti giberelin seperti paklobutrazol dan cycocel teruji efektif meningkatkan jumlah umbi tanaman kentang.

Berdasarkan analogi tersebut, agaknya senyawa theobroksida memiliki prospek yang baik untuk diteliti lebih jauh agar dapat diaplikasikan pada tanaman-tanaman bernilai ekonomis lebih tinggi sebagaimana halnya tanaman kentang.

\section{SIMPULAN}

Aplikasi filtrat cendawan Lasiodiploida theobromae yang lebih dikenal senyawa theobroksida menunjukkan pengaruh dengan cara menekan pertumbuhan tanaman pada peubah tinggi tanaman, luas daun dan jumlah daun bayam (Amaranthus spp. L.) Efek penghambatan menurun seiring dengan penurunnya konsentrasi filtrat. Konsentrasi 300 ppm menunjukkan efek penekatan terkuat terhadap partumbuhan tinggi tanaman $(21,1 \mathrm{~cm})$, luas daun $\left(48,6 \mathrm{~cm}^{2}\right)$ per tanaman dan jumlah daun 10 , 2 helai per tanaman.

\section{UCAPAN TERIMAKASIH}

Terimakasih disampaikan kepada Direktorat Jenderal Pendidikan Tinggi yang telah memfasilitasi penelitian ini melalui Program Desentralisasi Penelitian Hibah
Bersaing DIPA Kopertis Wilayah I tahun 2015.

\section{DAFTAR PUSTAKA}

Chaney, E.R. 2004. Paclobutrazol : More Than ust a Growt Retardan . Pro Hort Conference, Peoria, Illinois. Purdue University.

Chen, S., H. Shiwachi, A. Sanada, andH. Toyohara. Theobroxide and day-length effects on the growth of yam (Diooscorea spp.) J. ISSAAS. Vol 16. No. 1 : $22-30$.

Ewing, E. E., and P. C. Struik. 1992. Tuber formation in potato: Indduction, initiation, and growth. Hort. Rev.14:89197.

Gao, X., Yang C. Minami, H. Matsuura, A. Kimura and T. Yoshihara. 2003. Inhibitory effect of salicylhydroxamic acid on theobrroxide-induced potato tuber formation. Plant Science, 165 (5) : 993-999.

Kong, F., J. Abe, K. Takanashi, H. Maatsura, T. Yoshihara, and K. Nabeta, 2005 Allene oxidecyclase is essential for theobroxideinduced jasmonic acid biosynthesis in Pharbitis nil. Biochemical and Biophysical Research Communications, 336 (4) : 1150-1156.

Kong, F., X. Gao, K.H. Nam, K. Takahashi, H/ Matsuura, and T. Yoshihara. 2005 b. Theobroxide inhibits stem elogationin pharbitis nil by regulating jasmonic acid and gibberelin biosynthesis. Plant Science. 169 (4) : 721-725.

Larekeng, S. H. 2008. Pemanfaatan Filtrat Cendawan Diplodia spp. Sebagai Penginduksi Umbi Mikro Kentang Secara in vitro. PPs UNHAS. Makasar. 
Salesbury, F. B, and C. W. Ross. 1995. Fisiologi Tumbuhan, Jilid III terjemahan Diah R. Lukman dan Suwaryo. Institut Teknologi Bandung, Bandung.

Yoshihara, T., F. Ohmori, K. Nakamori, M. Amanuma, T. Tsutsumi, A. Ichihara, and $\mathrm{H}$. Matsuura. 2000. Induction of plant tubers and flower buds under noninducing photoperiod conditions by a natural product, theobroxide. J. Plant Growth Regul., 19:457-461.

Yang, Q., X. Gao, Y. Fujino, H. Matsuura, and T. Yoshihara. 2004. Effects of theobroxide, a natural product, on the level of endogenous jasmonoids. $Z$. Natuforsch, $59: 828-838$.

Yoshihara, T., F. Ohmori, K. Nakamori, M. Amanuma, T. Tsutsumi, A. Ichihara, and H. Matsuura. 2000. Induction of plant tubers and flower buds under noninducing photoperiod conditions by a natural product, theobroxide. J. Plant Growth Regul., 19: 457- 461.

Weaver, R.J. 1972. Plant Growth Substances in Agriculture. W. H. Freeman. San Francisco. P.594. 